\title{
Correction: Primary and secondary school teachers' perceptions of their social science training needs
}

\author{
Raquel Sánchez-Ibáñez (1), Catalina Guerrero-Romera \& Pedro Miralles-Martínez (1)
}

Correction to: Humanities and Social Sciences Communications https://doi.org/10.1057/s41599-021-00705-0, published online 25 January 2021.

The original acknowledgement was incomplete and read as:

This project has been carried out through the funding of two ongoing projects and to whose teams the authors belong. The first entitled "Methodological concepts and active learning methods for the improvement of teaching skills of teachers (PGC2018-094491-B-C33)" is funded by the Spanish Ministry of Science, Innovation and Universities, directed by Pedro Miralles Martínez and Cosme Jesús Gómez Carrasco. Participating entities are the University of Murcia, University of Valencia and University of Santiago de Compostela. The second is funded by the Seneca Foundation for Science and Technology in the Region of Murcia and is entitled "Geographic and historical thinking of primary school students in the Region of Murcia: an innovative methodological proposal for quality education (20874/PI/18", under the direction of Pedro Miralles Martínez (University of Murcia).

It has now been corrected to:

This project was carried out through the funding of two ongoing projects and to whose teams the authors belong. The first entitled "Methodological concepts and active learning methods for the improvement of teaching skills of teachers (PGC2018-094491-B-C33) (MCI/AEI/FEDER, UE) is funded by the Ministry of Science, Innovation and Universities, co-financed with FEDER (UE) funds and directed by Pedro Miralles Martínez and Cosme Jesús Gómez Carrasco. Participating entities are the University of Murcia, University of Valencia and University of Santiago de Compostela. The second is funded by the Seneca Foundation for Science and Technology in the Region of Murcia and is entitled "Geographic and historical thinking of primary school students in the Region of Murcia: an innovative methodological proposal for quality education (20874/PI/18)”, under the direction of Pedro Miralles Martínez (University of Murcia).

Published online: 01 March 2021

Open Access This article is licensed under a Creative Commons Attribution 4.0 International License, which permits use, sharing, adaptation, distribution and reproduction in any medium or format, as long as you give appropriate credit to the original author(s) and the source, provide a link to the Creative Commons license,
and indicate if changes were made. The images or other third party material in this article are included in the article's Creative Commons license, unless indicated otherwise in a credit line to the material. If material is not included in the article's Creative Commons license and your intended use is not permitted by statutory regulation or exceeds the permitted use, you will need to obtain permission directly from the copyright holder. To view a copy of this license, visit http://creativecommons.org/licenses/by/4.0/.

(c) The Author(s) 2021 